\title{
Response of Seed Rates and Row Spacing on Growth, Yield and Yield Components of Wheat (Triticum aestivum L.) Crop
}

\author{
Anbessie Debebe Abboye Asrat Mekonnen Teto* \\ Kulumsa Agricultural Research Center, Ethiopian Institute of Agricultural Research, \\ P. O. Box 489, Asella, Ethiopia
}

\begin{abstract}
The main goal of this review study is to provide an overview of wheat production management requirements in general and specifically in Ethiopia, comparing with current research trends and to make some recommendations on the appropriate seed rates for growth, yields, and grain quality wheat. This paper reviewed that application of a well-balanced seed rates under optimum environment availability of which may help in improving growth, yield and grain quality of wheat. To optimize seed rate and plant density of wheat, some experiments have conducted so far across most wheat growing areas of Ethiopia. The field experiments were carried out in different times at Kulumsa Agricultural Research Center from July to November 2012 and from June to November 2018 cropping seasons. Four varieties (Digalu, Dandea, Kekeba and Shorima) and five seed rates $(100,125,150,175,200 \mathrm{~kg}$ ha-1) The experiment was laid out as a randomized complete block design with a factorial arrangement and replicated three times. On the hand, in the 2018 cropping season, three bread wheat varieties (Shorima, Dendea and Hidassie representing different seed sizes of small, medium, large respectively and four plant populations of 250, 300, 350 and 400 seeds m-2 were tested. Four levels of seed rates $(75,100$, 125 and $150 \mathrm{~kg} / \mathrm{ha})$ and three row spacing $(20,25$ and $30 \mathrm{~cm})$ were tried. the same type of experimental studies with the same nature of objectives were also carried out during the 2015 main cropping season at Awtaro Woreda, Wolaita Zone, The result of the experiments showed significant difference for number of tillers, plant height, grain yield, and seed test weight. But using of different row spacing had no significant effect on parameters that have been taken except the plant height; however plant height, number of tiller per plant, spikelet per spike, grains per spike, biological yield, grain yield \& straw were significantly affected by different seed rate. But since the current results are gained from just one crop in some limited districts, conducting repetitive field experiments on different crops other than wheat at the wide-ranging of regions in the national level is suggested in order to confirm the current results on different crops $\&$ in the entire farming lands of the country.
\end{abstract}

Keywords: Plant Population, Row Spacing, Seed Rate, Variety, Wheat Yield

DOI: $10.7176 / \mathrm{JNSR} / 10-3-05$

Publication date: February $29^{\text {th }} 2020$

\section{INTRODUCTION}

Wheat (Triticum aestivum L.) is one of the most important cereal crops of the world and is a staple food for about one third of the world's population (Hussain and Shah, 200). Wheat is primarily used as a staple food providing more protein than any other cereal crop (Iqtidar et al., 2006). However, one challenge for global nutrition is to increase grain yield per unit area while maintaining its end use value Wheat is grown on larger area than any other crop and its world trade is greater than for all other crops combined. Its world trade is greater than for all other crops combined. It is easily stored and transported (Slafer and Satorre, 1999).

In Ethiopia, it is largely grown in the highlands of the country and constitutes roughly $10 \%$ of the annual cereal production and plays an appreciable role in supplying the population with carbohydrates, protein and minerals (Schulthess et al., 1997). The crop is grown at an altitude ranging from 1500 to 3000 meters above sea level (masl), between 6-160 N latitude and 35-420 E longitudes. The most suitable agro- ecological zones, however, fall between 1900 and 2700 meters above sea level (Bekele et al., 2000). The major wheat producing areas in Ethiopia are located in Arsi, Bale, Shewa, Ilubabor, Western Hareghe, Sidamo, Tigray, Northern Gonder and Gojam zones (Bekele et al., 2000).Among the factors responsible for low wheat yield, delay in sowing, traditional sowing methods, low seed rate and improper row spacing are very important (Iqba et al., 2010). Many farmers in developing countries prefer to use a higher seed rate than recommended, because they perceive it as a good strategy to control weeds and reduce the risks of crop production.

If the row is too wide, the crop is unable to rapidly shade the inter-row area to capture sunlight and weeds quickly become established. If the row is too narrow, inter-row crop competition results in poorer yields, difficulties in disease and insect control, and greater likelihood of lodging. These resulted for reduction in both yield and quality of wheat. In view of these reasons, such very necessary review was initiated at the above mentioned parameter ranges with the following objectives:

\subsection{Objectives:}

The principal objective of this review paper was: 
- To review the literatures which are related to the response of seed rates and plating methods of bread wheat with the intention to use them as a theoretical background for future research work.

- To provide an overview of wheat crop production management requirements for the appropriate seed rates of bread wheat crop.

- To make some appropriate recommendations on the economically suitable row spacing and sowing method for the growth, yield and yield components of bread wheat.

\section{BODY OF DISCUSSION}

\subsection{The Methodology Used for this Review Paper}

The required research outputs on the response of seed rates and plating methods of bread wheat were gathered from all accessible sources such as internet, scientific papers, books, periodical publications and collected also through formal and informal interviews from potential informers in order to summarize and compile in the right reviewing ways and methodologies. All the research findings on the "Response of Seed Rates and Row Spacing on Growth, Yield and Yield Components of Bread Wheat" are thoroughly reviewed and discussed by comparing with the relevant literatures all with helped by the given guide lines of the course adviser.

\subsection{History \& Evolutionary Processes of Bread Wheat}

The process, which began some ten thousand years ago, involved the following major steps. Wild einkorn (T.urartu) crossed spontaneously with Goat grass 1 (Aegilops speltoides) to produce Wild Emmer ( $T$. dicoccoides;) further hybridizations with another Aegilops (A. taushi), gave rise to Spelt (T. spelta) and early forms of Durum Wheat (cultivated emmer); Bread Wheat (T. aestivum) finally evolved through years of cultivation in the southern Caspian plains. This evolution was accelerated by an expanding geographical range of cultivation and by human selection, and had produced bread wheat as early as the sixth millennium BC. Modern varieties are selections caused by natural mutation starting with emmer wheat up to husk less modern wheat.

It is believed that T. monoccocum naturally hybridized with the yet unknown B- genome donor to give rise to the tetraploid emmer group. Emmer wheat in turn hybridized with Ae. squarossa and a spontaneous chromosome doubling of the triploid resulted in the formation of hexaploid wheat (Feldmann, 2001). The other forms, such as $T$. durum, $T$. turgidum and T. polonicum might have originated from cultivated emmer through mutation or accumulation of mutations that reduced the toughness of the glumes to a point at which freethreshing was attained (Kimber and Sears, 1987).

At the tetraploid level, two main species have been recognized; T. timopheevi (AAGG) and T. turgidum (AABB). T. durum belongs to the latter group. There are many known wild and cultivated species in the genus Triticum. However, the principal wheats of commercial importance are T. aestivum and T. durum (Hanson et al., 1982).

\subsection{Overview of Wheat Production and Its Importance}

Wheat is the leading grain and most important food crop. Its importance was derived from the properties of its gluten, a cohesive network of touch endosperm proteins that stretch with the expansion of fermenting dough, yet coagulates and holds together when heated to produce a risen loaf of bread. Only wheat, and to a lesser extent rye and triticale, have this property. It is utilized for making bread, flour confectionery products (cakes, cookies, and pretzels), unleavened bread, semolina, bulgar, and breakfast cereals. Its diversity of uses, nutritive content, and storage qualities has made wheat a stable food for more than one-third of the world's population

\subsection{Wheat Production Status in Ethiopia}

Ethiopia is one of the principal producers and importers of wheat in East, Central and Southern Africa (Tanner and Mwangi, 1992). The two economically important wheat species grown in Ethiopia are tetraploid durum wheat (Triticum durum) and hexaploid bread wheat (T. aestivum). The production of bread wheat dominates the peasant farming systems in the mid to high altitude zones (Tanner et al., 1994). Its production is increasing rapidly (Amsal et al., 1995; CSA, 2000) due to both a high local demand, and the availability of high-yielding, input-responsive cultivars adapted to heterogeneous environmental conditions (Hailu, 1991).

Area coverage of bread wheat has substantially expanded mainly by replacing unimproved, input nonresponsive traditional cereal crops such as teff (Eragrostis tef), durum wheat (T. durum) and barley ( Hordeum vulgare ). Recently-released bread wheat cultivars are highly responsive to improved management systems, and, relative to older wheat lines, show an economic response to higher rates of nutrient application.

\subsection{Response of Rates \& Raw Spacing on Growth and Yields of Wheat}

Proper row spacing and seed rate are most important management factor affecting the agronomic characteristics of wheat (Ansari et al., 2006, Marwat et al., 2002, Chaudhary et al., 2000). Late seeding dates normally result in higher seeding rates because a delay in sowing normally reduces individual plant growth and tiller production 
(Gooding and Davies, 1997; Satorre, 1999).

Suitable combination of seed rate and row spacing could increase grain yield of wheat (Marshall and Ohm, 1987), whereas seeding rates alone did not influence the grain yield (Rafique, et al., 1997) much.

According to Ali et al., (1996), seed rate of 100-125 $\mathrm{kg} \mathrm{ha}^{-1}$ with row spacing of 12.5 - $25 \mathrm{~cm}$ guaranteed maximum grain yield of wheat.

They found that tillers were more in wider row spacing $(37.5 \mathrm{~cm})$ followed by $25 \mathrm{~cm}$ and $12.5 \mathrm{~cm}$ row spacing. Chaudhary et al, (2000) reported that seed rate of $150 \mathrm{~kg} \mathrm{ha}^{-1}$ increased the number of grains spike-1 and depressed the number of fertile tillers $\mathrm{m}^{-2}$. Khan et al. (2001) reported higher wheat yield at seed rate of 100$150 \mathrm{~kg} \mathrm{ha}^{-1}$ in $27 \mathrm{~cm}-13.5 \mathrm{~cm}$ a part rows, respectively. Assenheimer et al., (1999) reported that row spacing of $20 \mathrm{~cm}$ resulted in significantly higher wheat grain yield in comparison with $30 \mathrm{~cm}$ row spacing; however, seed rate did not have effect on wheat yield.

After conducting field trials on two wheat cultivars, Malik et al. (1996) concluded that grain and straw yields were high with $15 \mathrm{~cm}$ row spacing and decreased with increased row spacing while harvest index was not affected significantly by row spacing. Arif et al., (2003) suggested $150 \mathrm{~kg} \mathrm{ha}^{-1}$ seed rate with $22.5 \mathrm{~cm}$ row spacing for maximum wheat yield. They also found that plant height, grains spike, and 1000-grain weight decreased with increase in seed rate, however, tillering increased with increasing seed rate.

Research results have shown that yields of wheat \& barley increased as the spacing between rows is decreased similarly narrow row spacing consistently produced higher grain yield than widen row spacing (Chen and Neill., 2006. Johnson \& Hargrove, 1988) whereas Ahmad et al. (2003) concluded that maximum grain yield $\&$ harvest index of wheat can be obtained with row spacing of $20 \mathrm{~cm}$. Increasing seed rate of wheat from 100 to $200 \mathrm{~kg} \mathrm{ha}^{-1}$ increased the grain and straw yields (Kumpawt, 1998).

\subsection{Effect of Seed Rate on Growth, Yield and Yield Components of Wheat}

Seeding rate can impact on wheat tillering, grain yield and protein quality (Staggenborg et al., 2003). Hence, achieving higher agronomic performance and better end-use quality requires optimizing and periodically reviewing management practices such as seeding rates. It was reported that, in a dense wheat population, grain yield was decreased due to competition between plants that induced self-regulation (Jennifer et al., 2006). However, in cultivars that produce fewer tillers, higher seeding rates compensated for reduced tiller and promoted more main stem spikes (Staggenborg et al., 2003).

Days to $50 \%$ heading, days to $90 \%$ physiological maturity, plant height, spike length, hectoliter weight and Harvest Index $(\mathrm{HI})$ were affected highly significantly $(\mathrm{p}<0.01)$ by the main effects of variety and seed rate whereas, grain protein content was affected highly significantly $(p<0.01)$ only by variety and above ground dry biomass yield was affected highly significantly $(p<0.01)$ only by the main effect of the seed rate. (Jemal Abdulkerim, Tamado T. et al., 2015).

Furthermore, the interaction effect of variety and seed rate significantly affected thousand kernels weight, number of effective tillers and number of kernels per spike and grain yield. The use of $150 \mathrm{~kg}$ ha seed rate for variety Shorima resulted in highest thousand kernels weight (39.48 g), number of kernels per spike (60.23) and grain yield (5339.3 kg ha). From the result of this study, the use of $125 \mathrm{~kg}$ ha seed rate for variety Danda'a; 150 $\mathrm{kg}$ ha for varieties Shorima and Kakaba and $175 \mathrm{~kg}$ ha for variety Digalu were identified for good crop stand and finally the yield. (Jemal Abdulkerim, Tamado T. et al., 2015). Wheat quality was not reduced at higher seeding rates as protein content, kernel weight and test weight were unaffected (Jennifer et al., 2006: Bryan, 2001).On the other hand, it was stated that protein concentration declined as seeding rates and yields increased (Samuel, 1990: Geleta et al., 2002).

The decrease in plant height in response to lowering the seeding rate to $100 \mathrm{~kg} \mathrm{ha}^{-1}$ may reflect formation of more secondary tillers in less populated stands, which tend to be shorter in stature. At the highest seeding density, the increased intra-plant competition may have contributed to the reduction in plant height. Chaudhary et al, (2000) and Arif et al, (2003) reported that increased tillers with increase in seed rate. The results are also in line with Rafique et al., (1997), who observed linear increase in the number of tillers as the seed rate was increased. The results are in line with Ali et al, (1996), Chaudhary et al, (2000) and Rafique et al, (1997) who explained that lower seeding rates significantly increased the number of grains and vice versa. By increasing seed rate the number of grains spike ${ }^{-1}$ is reduced (Khan et al, (2002) and Mehrvar and Asadi, 2006). Mehrvar and Asadi (2006) concluded that by increasing seed rate the 1000- grains weight is reduced. These results are in analogy with the findings of earlier workers (Arif et al., 2003), who reported higher yield with seed rate of $150 \mathrm{~kg} \mathrm{ha}^{-1}$, however disagree with those of Rafique et al., (1997) who concluded that seeding rates did not influence the grain yield of wheat.

\subsection{Response of Raw Spacing on Growth, Yield and Yield Component of Wheat}

It is well recognized that by keeping proper row spacing and inputs like varieties, fertilizers and seed rate etc. Fatyga (1991) reported that highest average yields of 2.85-2.92 $\mathrm{t} \mathrm{ha}^{-1}$ were obtained with $25 \mathrm{~cm}$ row spacing. 
Rajput et al, (1989) reported that maximum grain yield was obtained when wheat was sown at row spacing of 30 $\mathrm{cm}$. Higher sowing rates coupled with decrease in row spacing increased the number of tillers $\mathrm{m}^{-2}$ and grain yields. Solie et al., (1991) investigated that decreasing row spacing significantly increased wheat yields. Most research results reveald that grain yield increased as row spacing decreased. Grain yield progressively decreased as row spacing increased, but was not affected by row spikes $\mathrm{m}^{-2}$ was the yield component most affected by row spacing.

\subsection{Nutrient Requirements of Wheat Crop}

Sustainable agricultural system is one that is economically viable, offers nontoxic, nutritious food, and preserves resources and improves the environment (Campbell et al., 2004). Fertilizers are the fundamentals to produce more crop yields from the existing farming lands. The economic and conservational significances of the uncertain nutrients usage by crops calls for nontoxic fertilization and that nutrient needs of crops is in keeping with their physiological requirements and predictable yields (Ryan, 2008). Fertilizer needs of crops differ with fertility status of the soil, obtainability of soil moisture, variety of the crop, persistence for which the crop is grown, etc. of several reasons, fertility status of the soils significantly affecting crops yield. Various rates and types of isolates of rhizobia and their benefit have been presumed beneficial in regard to soil resource improvement and increase yield and yield components (Gobena N., Anbessie D., et al., 2019). Modern agriculture wiped out its sustainability owing to excess use of chemical fertilizers and dangerous pesticides further leading to higher cost of farming, declined food security and welfare, and finally the decline in soil Fertility (Saritha and Prasad Tollamadugu, 2019). Organic nitrogen fixation is a central life supportive process that provides most of the fixed nitrogen required to sustain life. Animals, including humans, depend on plants to supply a great deal of the energy and nitrogenous compounds required for survival. Plants are similarly reliant on the availability of nitrogenous combinations formed from atmospheric $\mathrm{N}_{2}$ either commercially or biologically by microbes. In this way, nitrogen fixation assumes significant importance in agriculture for the reason that good crop yields depend on an ample supply of fixed nitrogen by which the biological process gives about $65 \%$ of the total annual yield of fixed nitrogen (Fisher and Newton, 2002; Gobena Negasa, Anbessie Debebe, et al., 2019).

\subsection{Economic Analysis of Bread Wheat Grain Yields}

The Economic analysis results have been indicated a consistent profitable response on grain yield of bread wheat. Relating to the partial budget analysis results, the highest net benefit value (46735 ETB ha-1) was obtained from the variety Hidassie at a seed rate of 300 seeds $\mathrm{m}^{-2}$, followed by the net benefit value (44460 ETB ha-1) was obtained from the variety Hidassie at a seed rate of 250 seeds $\mathrm{m}^{-2}$ and the lowest grain yield (30117 ETB ha-1) was obtained from the variety Hidassie at seed rate of 400 seeds $\mathrm{m}^{-2}$. The results of the partial budget analysis and the economic data used in the development of the partial budget are illustrated in (Anbessie Debebe., Abebe Megersa, and Dechassa Hirpa 2019).

\subsubsection{Partial Budgeting Analysis of Bread Wheat Grain Yields}

In order to organize the experimental data and information about the costs and benefits of various alternative treatments, a partial budget analysis was done to determine the economic impact of various alternative treatments as compared to the farmers' practice for bread wheat production at the study area. Local market (LM) price was used to calculate the product value. The cost of labor for weeding was taken at 35.00 ETB per day. Considering the costs that varied (cost of seed, fertilizers, chemicals and labor wage for planting, weeding and harvesting), the farmers' practice had a lower cost than the experimental method.

In the partial budgeting analysis result of the present study, the costs for the different plant population levels varied according to their rates requirements being other costs were constant for each treatment. In order to recommend the present results for the study area, it is necessary to estimate the minimum rate of return acceptable to farmers or producers in the recommendation domain. Based on partial budget analysis, the highest net benefit (46735 ETB ha-1) was obtained from treatment combination of variety Hidassie/large seed size/ with a seed rate of 300 seeds $\mathrm{m}^{-1}$, followed by net benefit (44460 ETB ha ${ }^{-1}$ ) was obtained from the treatment combination of variety Hidassie/large seed size/ with a seed rate of 250 seeds $/ \mathrm{m}^{-2}$, while the lowest net benefit (30117 ETB/ha $\left.{ }^{-1}\right)$ was also obtained from the combination of variety Hidassie/large seed size/ with a seed rate of 400 seeds $/ \mathrm{m}^{-2}$ only in one growing season as shown on (Table 1).

\subsubsection{Benefit to Cost Ratio Analysis (BCR)}

The benefit-cost ratio analysis was used in the cost-benefit analysis in order to summarize the overall relationship between the relative costs and benefits of the proposed research project in which the BCR was expressed in monetary terms.

The alternatives are not simply ranked but can be quantitatively assessed one against the other. The highest benefit cost ratio of (7.57) with low marginal cost and more profitable MRR (795\%) was obtained from the variety Hidassie/large seed size/ at the use of 300 seeds $\mathrm{m}^{-2}$ seeding rate followed by (7.55) benefit cost ratio with the advantageous MRR (899\%) was recorded from the variety Hidassie/large seed size/ at seeding rate of 
250 seeds $\mathrm{m}^{-2}$ respectively (Table 9 and 10). Therefore, the most economical seed rates for small scale farmers of the study area with low cost of production and higher benefits in this case were 300 and 250 seeds $\mathrm{m}^{-2}$ seeding rates of variety Hidassie/large seed size/ respectively (Anbessie Debebe, Abebe Megersa, and Dechassa Hirpa 2019).

Table 1. Partial Budgeting Analysis of Bread Wheat Grain Yields.

\begin{tabular}{|c|c|c|c|c|c|c|c|c|}
\hline $\begin{array}{c}\text { Treatmen } \\
\text { No }\end{array}$ & Variety & $\begin{array}{c}\text { Plant } \\
\text { population } \\
\mathrm{ha}^{-1}\end{array}$ & $\begin{array}{l}\text { Average } \\
\text { grain } \\
\text { yield } \\
(\mathrm{kg} / \mathrm{ha})\end{array}$ & $\begin{array}{l}\text { Adjusted } \\
\text { grain } \\
\text { yield } \\
\text { ( kg/ha) }\end{array}$ & $\begin{array}{c}\text { Total } \\
\text { costs } \\
\text { that } \\
\text { varied } \\
(\mathrm{ETB} / \mathrm{ha})\end{array}$ & $\begin{array}{c}\text { Gross } \\
\text { farm } \\
\text { benefit } \\
(\mathrm{ETB} / \mathrm{ha})\end{array}$ & $\begin{array}{c}\text { Net } \\
\text { benefit } \\
\text { value } \\
(\mathrm{ETB} / \mathrm{ha})\end{array}$ & $\begin{array}{c}\text { Benefit } \\
\text { to } \\
\text { cost } \\
\text { ratio } \\
\text { (ETB) }\end{array}$ \\
\hline 1 & Shorima & $\begin{array}{l}2500000 \\
\text { seeds }\end{array}$ & 3930 & 3341 & 5382 & 43433 & 38051 & 707 \\
\hline 2 & Shorima & $\begin{array}{l}3000000 \\
\text { seeds }\end{array}$ & 4346 & 3694 & 5656 & 48022 & 42366 & 7.49 \\
\hline 3 & Shorima & $\begin{array}{l}3500000 \\
\text { seeds }\end{array}$ & 4322 & 3674 & 6001 & 47762 & 41761 & 6.96 \\
\hline 4 & Shorima & $\begin{array}{l}4000000 \\
\text { seeds }\end{array}$ & 4059 & 3450 & 6178 & 44850 & 38672 & 6.26 \\
\hline 5 & Dendea & $\begin{array}{l}2500000 \\
\text { seeds }\end{array}$ & 4134 & 3514 & 5595 & 45682 & 40087 & 7.16 \\
\hline 6 & Dendea & $\begin{array}{l}3000000 \\
\text { seeds }\end{array}$ & 4045 & 3438 & 5931 & 44694 & 38763 & 6.54 \\
\hline 7 & Dendea & $\begin{array}{l}3500000 \\
\text { seeds }\end{array}$ & 4485 & 3812 & 6236 & 49556 & 43320 & 6.95 \\
\hline 8 & Dendea & $\begin{array}{l}4000000 \\
\text { seeds }\end{array}$ & 4865 & 4135 & 6572 & 53755 & 47183 & 7.18 \\
\hline 9 & Hidassie & $\begin{array}{l}2500000 \\
\text { seeds }\end{array}$ & 4556 & 3873 & 5889 & 50349 & 44460 & 7.55 \\
\hline 10 & Hidassie & $\begin{array}{l}3000000 \\
\text { seeds }\end{array}$ & 4788 & 4070 & 6175 & 52910 & 46735 & 7.57 \\
\hline 11 & Hidassie & $\begin{array}{l}3500000 \\
\text { seeds }\end{array}$ & 3643 & 3097 & 6541 & 40261 & 33720 & 5.16 \\
\hline 12 & Hidassie & $\begin{array}{c}4000000 \\
\text { seeds }\end{array}$ & 3350 & 2848 & 6907 & 37024 & 30117 & 4.36 \\
\hline
\end{tabular}

Note: Cost of seed 15.25 ETB/kg; Labor Cost ETB 35/day; Field Sales price ETB 13.00/kg

\subsubsection{Adjusted Grain Yield Analysis of Bread Wheat $\left(\mathrm{kg} \mathrm{ha}^{-1}\right)$}

The adjusted yield is the average yield adjusted downward by a certain percentage to reflect the difference between the experimental yield and the yield farmers could expect from the treatment.

Experimental yields, even from on-farm experiments under representative conditions, are often higher than the grain yields that farmers could expect using the same treatments (CIMMYT, 1988). There are several reasons for yield adjustment insistences and just to emphasize two key points:

a). Management: Researchers can often be more precise and sometimes more timely than farmers in operations such as plant spacing, fertilizer application, or weed control.

b). Plot size: Yields estimated from small plots often overestimate the yield of an entire field because of errors in the measurement of the harvested area and because the small plots tend to be more uniform than the farmers large fields.

\subsubsection{Dominance Analysis of Bread Wheat Grain Yields}

Dominance analysis procedure was carried to select potentially profitable treatments from the range that was tested. It was done first by listing the treatments in order of increasing costs that vary as shown on (Table 2). Any treatment that had net benefits that are less than or equal to those of a treatment with lower costs that vary is dominated. Then the dominated treatments were eliminated from further economic analysis. It led to the selection of treatments, Hidassie/large seed size/ at seed rate of 250 and 300 seeds $\mathrm{m}^{-2}$, which ranked in equal order of the BCR respectively. The marginal rate of return for non-dominated treatments is stated in (Table 3 ). MRR among treatments of the variety Hidassie at seed rate of 300 seeds $\mathrm{m}^{-2}$ were lower than that of the treatments in the variety Hidassie at seed rate of 250 seeds $\mathrm{m}^{-2}$. It was finally to in that order would give positive MRR of $795 \%$ and $899 \%$ respectively (Anbessie Debebe, Abebe, Dechassa Hirpa 2019). 
Table 2. Dominance Analysis of Bread Wheat Grain Yields

\begin{tabular}{|c|c|c|c|c|c|}
\hline $\begin{array}{c}\text { Treatment } \\
\text { No. }\end{array}$ & $\begin{array}{c}\text { Variety/Seed } \\
\text { Size }\end{array}$ & PPL & TVC (ETB/ha) & NBV (ETB/ha) & Dominance \\
\hline 1 & Shorima/Small & 250 seeds $\mathrm{m}^{-2}$ & 5382 & 38051 & \\
\hline 5 & Dendea/Medium & 250 seeds $\mathrm{m}^{-2}$ & 5595 & 40087 & \\
\hline 2 & Shorima/Small & 300 seeds $\mathrm{m}^{-2}$ & 5656 & 42366 & \\
\hline 9 & Hidassie/Large & 250 seeds $\mathrm{m}^{-2}$ & 5889 & 44460 & \\
\hline 6 & Dendea/Medium & 300 seeds $\mathrm{m}^{-2}$ & 5931 & 38763 & Dominated \\
\hline 3 & Shorima/Small & 350 seeds $\mathrm{m}^{-2}$ & 6001 & 41761 & Dominated \\
\hline 10 & Hidassie/Large & 300 seeds $\mathrm{m}^{-2}$ & 6175 & 46735 & \\
\hline 4 & Shorima/Small & 400 seeds $\mathrm{m}^{-2}$ & 6178 & 38672 & Dominated \\
\hline 7 & Dendea/Medium & 350 seeds $\mathrm{m}^{-2}$ & 6236 & 43320 & Dominated \\
\hline 11 & Hidassie/Large & 350 seeds $\mathrm{m}^{-2}$ & 6541 & 33720 & Dominated \\
\hline 8 & Dendea/Medium & 400 seeds $\mathrm{m}^{-2}$ & 6572 & 47183 & \\
\hline 12 & Hidassie/Large & 400 seeds $\mathrm{m}^{-2}$ & 6907 & 30117 & Dominated \\
\hline
\end{tabular}

Note: $P P L=$ plant population level; $T V C=$ total variable cost; $N B V=$ net benefit value.

The changes to the variety Shorima at plant population levels of $250 \mathrm{seed} \mathrm{m}^{-2}$ is eliminated for this reason to remain with changes to the variety Hidassie/ at plant population levels of 250 and $300 \mathrm{seeds} \mathrm{m}^{-2}$ which gave more than $100 \%$ MRR as promising new practices for farmers under the prevailing price structure (Table 10). According CIMMYT (1988), the minimum acceptable marginal rate of return (MRR) should be $100 \%$.

Table 3. Marginal Analysis Effects of Bread Wheat Grain Yield.

\begin{tabular}{|c|c|c|c|c|c|}
\hline Variety Seed Size and PPL & $\begin{array}{c}\text { TVC } \\
(\mathrm{ETB} / \mathrm{ha}\end{array}$ & $\begin{array}{c}\mathrm{MC} \\
(\mathrm{ETB} / \mathrm{ha})\end{array}$ & $\begin{array}{c}\text { NBV } \\
\text { (ETB/ha) }\end{array}$ & $\begin{array}{c}\text { MNB } \\
(\mathrm{ETB} / \mathrm{ha})\end{array}$ & $\begin{array}{l}\text { MRR } \\
(\%)\end{array}$ \\
\hline 1. Shorima/Small x 250 Seeds $\mathrm{m}^{-2}$ & 5382 & & $38051^{\sqrt{ }} \mathbf{E}$ & & \\
\hline 5. Dendea/Medium x 250 Seeds $\mathrm{m}^{-}$ & 5595 & 213 & $40087^{\sqrt{ }} \mathbf{E}$ & 2036 & 956 \\
\hline 2. Shorima/Small x 300 Seeds $\mathrm{m}^{-2}$ & 5656 & 61 & $42366^{\sqrt{ }} \mathbf{E}$ & 2279 & 3736 \\
\hline 9. Hidassie/Large $x 250$ Seeds $\mathrm{m}^{2}{ }^{2}$ & 5889 & 233 & 44460 & 2094 & 899 \\
\hline 10. Hidassie/Large x 300 Seeds m- & 6175 & 286 & 46735 & 2275 & 795 \\
\hline 8. Dendea/Medium x 400 Seeds $\mathrm{m}^{-}$ & 6572 & 397 & $47183^{\vee} \mathbf{E}$ & 448 & 113 \\
\hline
\end{tabular}

Note: ${ }^{\sqrt{ }} \mathbf{E}=$ eliminated; $P P L=$ plant population level; $T V C=$ total variable cost; $N B V=$ net benefit value;

$M N B=$ marginal net benefit; $M R R=$ marginal rate of return .

As stated by CIMMYT (1988), recommendation is not necessarily based on the highest yield and even not based on the highest MRR. Recommendation is just based on the highest net benefit cost ratio and thus, the most economically superior variety and seed rate for farmers of the study area with low cost of production and the highest net benefits were identified to be the variety Hidassie/large seed size/ at seeding rate of $300 \mathrm{seeds}^{-2}$ $\left(142.00 \mathrm{~kg} \mathrm{ha}^{-2}\right)$. The seeding rate of 250 seeds $\mathrm{m}^{-2}\left(118 \mathrm{~kg} \mathrm{ha}^{-2}\right)$ of this variety was also profitable with the highest net benefit and recommended as $2^{\text {nd }}$ option. Consistent with the partial budgeting analysis results, it can be determined that the most profitable treatment was the variety Hidassie/large seed size/ which gave the highest benefit cost ratio of (7.57) and MRR (795\%) at seed rate of 300 seeds $\mathrm{m}^{-2}$ whereas, alternatively the MRR of (899\%) and benefit cost ratio (7.55) were attained also from the variety Hidassie/large seed size/ at seeding rate of 250 seeds $\mathrm{m}^{-2}$ (Anbessie Debebe Abboye, Abebe Megersa, and Dechassa Hirpa 2019), as shown on (Tables 1 \& 3).

Therefore, the changes to the variety Shorima/small seed size/ at a seed rate of 250 seeds $\mathrm{m}^{-2}$; Dendea/Medium seed size/ at a seed rate of 250 seeds $\mathrm{m}^{-2}$, Shorima/Small seed size/ at a seed rate of 300 seeds $\mathrm{m}^{-2}$ and Dendea/medium seed size/ at a seed rate of 400 seeds $\mathrm{m}^{-2}$ are eliminated for their low benefit cost ratio and to remain with the changes to the variety Hidassie/large seed size/ at seed rate of 300 and 250 seeds $^{-2}$. The yield of treatment 8 is higher than that of treatment 10 as shown on (Table 7), but the dominance analysis shows that the value of the increase in yield is not enough to compensate the increase in costs. Farmers would be better off using the lower seed rate with lower costs (Anbessie Debebe Abboye, Abebe Megersa, and Dechassa Hirpa 2019).

\section{CONCLUSION AND RECOMMENDATION}

All the recommendations which have suggested here in this paper are primarily addressed to the small scale farmers of the country as well as for all of other improved technology users in the country which are officially known under their agricultural development activities, are the focus this review paper in particular. 


\subsection{Conclusion}

With the objective of to determine the effect of seed rates and row spacing as well as plant population rates on the growth, yields and Grain quality of wheat, the field experiments were carried out in different times at Kulumsa Agricultural Research Center from July to November 2012 and from June to November 2018 cropping seasons. Four varieties (Digalu, Danda'a, Kakaba and Shorima) and five seed rates (100, 125, 150, 175, $200 \mathrm{~kg}$ $\left.\mathrm{ha}^{-1}\right)$ with three row spacing $(20,25$ and $30 \mathrm{~cm})$ were tried. The experiment was laid out as a randomized complete block design (RCBD) with a factorial arrangement and replicated three times. On the hand, in the 2018 cropping season, three bread wheat varieties (Shorima, Dendea and Hidassie representing different seed sizes of small, medium, large respectively and four plant populations of 250, 300, 350 and $400 \mathrm{seeds} \mathrm{m}^{-2}$ were tested.

Apart from this, the same type of experimental study with the same nature of objectives were also carried out during the 2015 main cropping season at Awtaro Woreda, Wolaita Zone on farmer's field, From the result of this studies, the use of $125 \mathrm{~kg} \mathrm{ha}^{-1}$ seed rate for variety Dende'a; $150 \mathrm{~kg} / \mathrm{ha}$ for varieties Shorima and Kekeba and $175 \mathrm{~kg} / \mathrm{ha}$ for variety Digalu were identified for good crop stand and the top crop yield. In general, from all of the studies, significant differences in grain yield and most of agronomic parameters of bread wheat were identified due to variety and seeding rates. Similar experiment with the same nature of objectives were also carried out at Kulumsa Agricultural Research Center from June to November 2018 main cropping season, with the objectives of to determine the optimum plant population rate by identifying the most cost-effective bread wheat variety. This study suggested that sowing bread wheat with large sized seeds such as the variety Hidassie was remarkably beneficial with most promising agronomic performance.

\subsection{Recommendation}

As the research results of this study, the use of $125 \mathrm{~kg} / \mathrm{ha}$ seed rate for variety Dendea; $150 \mathrm{~kg} \mathrm{ha}^{-1}$ for varieties Shorima, Kekeba and $175 \mathrm{~kg} \mathrm{ha}^{-1}$ for variety Digalu can be recommend for most areas of Arsi zone as well as for interrelated areas of the same agro-ecological conditions.

Moreover, depending on the agronomic performance and yield of different studies variety Shorima at 150 $\mathrm{kg} \mathrm{ha}^{-1}$ was advantageous. However, as this is one season and one location experiment, it has to be repeated over the wide-ranging agro-ecologies and seasons with consideration of cost of production to reach at conclusive recommendation.

Furthermore, the results of the reviewed experimental studies showed that using of different row spacing had no significant effect on parameters that have been taken except the plant height; however plant height, number of tiller per plant, spikelet per spike, grains per spike, biological yield, grain yield \& straw were significantly affected by different seed rates. The interaction of seed rate \& row spacing also did not show significant difference except for the plant height.

According to the research results of the Awtaro Woreda in Wolaita Zone, the use of $75 \mathrm{~kg}$ seed ha-1 resulted in the maximum plant height $(83.87 \mathrm{~cm})$, number of tillers per plant $(20.37) \&$ productive tillers per plant (2.30), however $100 \mathrm{~kg}$ seed ha-1 gave the highest biological yield (7.98t ha-1), grain yield (2.78 t ha-1) \& straw $\left(5.27 \mathrm{t} \mathrm{ha}^{-1}\right)$. But since the current results are gained from just one crop in some limited districts, conducting repetitive field experiments on different crops other than wheat at the wide-ranging of regions in the national level is suggested in order to confirm the current results on different crops \& in the entire farming lands of the country.

According to the research results of Kulumsa, The economic analysis of the experiment was brought to select the best combination of the variety Hidassie/large seed size/ at a plant population rate of $300 \mathrm{seeds}^{-2}$ $\left(142.00 \mathrm{~kg} \mathrm{ha}^{-1}\right)$ gave the greatest grain yield $\left(4070 \mathrm{~kg} \mathrm{ha}^{-1}\right)$ with low cost of production and higher net benefits and recommended tentatively as $1^{\text {st }}$ option for the study area.

On the other hand, the variety Hidassie/large seed size/ at a plant population rate of $250 \mathrm{seeds} \mathrm{m}^{-2}(118 \mathrm{~kg}$ $\mathrm{ha}^{-1}$ ) gave better yield $\left(3873 \mathrm{~kg} \mathrm{ha}^{-1}\right)$ with a slightly additional cost rather than the primarily recommended seed rate and it was recommended as a $2^{\text {nd }}$ option for the small scale farmers of the study area. However, since this study was only at one location for single cropping season it is advisable to conduct further research and it is better to repeat the experiment across locations, soil type, and over seasons to make reliable and acceptable recommendations for a wide-ranging of agro-ecological zones.

\section{ACKNOWLEDGEMENTS}

This study was self-sponsored project and does not financially supported by any internal or external funding agencies. The authors would like to acknowledge colleagues who work at Kulumsa Agricultural Research Center and Arsi University for their technical and analytical advices while conducting this study.

\section{REFERENCES}

Ahmed , J., M.I. Marwat and H.K. Ahmed. (2003). Effect of herbicides and row spacing on different traits of wheat (Triticum aestivum L.). Pakistan Journal of Weed Science Research. 9(1-2):33-40. 
Ali, M. A., R. Rehman, M. Siddique and M. Rashid. 1996. Effect of seed rate and row spacing on wheat yield. $J$. Agric. Res. 34(6): 351-357.

Anbessie Debebe Abboye, Abebe Megersa, Dechassa Hirpa 2019. Effect of Plant Population on Growth, Yields and Quality of Bread Wheat (Triticum aestivum L.) Varieties at Kulumsa in Arsi Zone, South-Eastern Ethiopia, Kulumsa Agricultural Research Center, Ethiopian Institute of Agricultural Research, P. O. Box 489, Asella, Ethiopia

Ansari, M.A.,H.R.Meman,S.D.Tunio and S.A.Keerio.2006. Effect of planting pattern on growth and yieldofwheat.PakistanJ.Agri.,Agril.Engg.,Vet.Sc.22(2).

Arif, M.,M. Ali,Q.M.Din, M.Akram and L.Ali.2003. Effect of different seed rates and row spacing on the growth and yield of wheat.J.Anim.Pl.Sci. 13(3):161-163.

Assenheimer,C.,B.Metzger,L.P apworth and G. Ragan.(1999). Agriculture and Agri-Food Canada Bulletin. The Alberta Farm Machinery Research Centre.

Bekele Hunde, Kotu,H.Varkuijl,W.Mwangiand D.G.Tanner.2000. Adaptation of improved wheat technologies in Adaba and Dodola woredas of the Bale highlands, Ethiopia. Mexico D.F: International Maize and Wheat Improvement Centre (CIMMYT) and Ethiopian Agricultural Research Organization (EARO).

Baloch, M. S., I.T .H. Shah, M. A. Nadim, M. I. Khan and A. A. Khakwani.2010. Effect of Seeding Density and Planting Time on Growth And Yield Attributes of Wheat. J.Anim.Pl.Sci. 20(4):239-240

Bryan, H.2001. Planting rate influence on yield and agronomic traits of harder spring wheat in north eastern North Dakota.NDSUAg.Report1, North Dakota State University.

Campbell, C.A., Myers, R.J.K., \& Curtin, D. 2004. Managing nitrogen for sustainable crop production. Earth and Environmental Science, 42(1-3), 277-296.

Chaudhary,M.A.,A.Ali,M.A.Siddique and R.Sohail.2000. Growth and yield response of wheat to different seed rates and wild oat(Avenafatua) competition durations.PakistanJ.Agri.Sci.37(3-4):152-154.

Chen, C.and K.Neill.2006. Response of spring wheat yield and protein row spacing, plant density and nitrogen application in Central Montana. Fertilizer Facts: No.37, Montana State University, Agricultural Experiment Station and Extension Service.

CSA, 2002. Agricultural sample survey: Report on area and production of major crops. Addis Ababa, Ethiopia.

Fatyga, J. 1991. Effect of different nitrogen fertilizer application rates and row spacing on the quantity andqualityofbuckwheatyields. 109:87-94.

Fisher, K. and Newton, W. E. 2002. Nitrogen Fixation- A General Overview. In: G. Jeffery Leigh (ed.) Nitrogen Fixation at the Millenniu. Elsevier.

Feldmann, M.2001. Origin of cultivated wheat. Pp.3 - 56.In A. P. Bonjean and W. J. Angus (Eds.).The world wheat book. A history of wheat breeding. Lavoiser Publishing, France.1

Geleta, B., M. Atak, P.S. Baenziger, L.A. Nelson, D.D. Baltenesperger, K.M., Eskridge, M.J. Shipman and D.R. Shelton.2002. Seeding Rate and Genotype Effect on Agronomic Performance and end-use Quality of Winter Wheat. Crop Sci. 42: 827-832.

Gobena Negasa, Anbessie Debebe, Amare Tadesse, Mengistu Chemeda, Dugasa Gerenfes, Asrat Mekonnen and Wendesen Melak, 2019. Determination of the Rate of Rhizobial Bio fertilizers for Faba Bean $(V$. faba), in the Major Growing Areas of Arsi Zone. Journal of Biology, Agriculture and Healthcare ISSN 2224-3208 (Paper) ISSN 2225-093X, Vol.9, No.21, www.iiste.org.

Gooding, M. J. and W.P.Davies.1997. Wheat production and utilization. CAB Int.,Walling ford, UK.

Hailu Gebre-Mariam. 1991. Wheat production and research in Ethiopia. pp.1-15. In : Hailu Gebre-Mariam, Tanner, D.G. and Mengistu Hulluka (eds.). Wheat Research in Ethiopia: A Historical Perspective. IAR/CIMMYT, Addis Ababa, Ethiopia.

Hanson, H., N.E. Borlaug and R.G. Anderson .1982. Wheat in the third world. Boulder, CO, USA, West views Press.

Iqbal, N., N. Akbar, M. Ali, M. Sattar and L. Ali. 2010. Effect of seed rate and row spacing on yield \& yield components of wheat (Triticum aestivium L.). Pakistan. J. Agric. Res., 48(2)

Jan,A.,M.Y.Khan,M.I.Marwat and T.Muhammed. 2000. Impact of intra-specific competition on the agronomic traits of wheat.Pakistan J.Biol.SCi,3;2016-2019

Jemal Abdulkerim, Tamado Tana and Firdissa Eticha. 2015. Response of Bread Wheat (Triticum aestivum L.) Varieties to Seeding Rates at Kulumsa, South Eastern Ethiopia. Asian Journal of Plant Sciences 14 (2): 50 58, 2015 ISSN 1682-3974; 2015 Asian Network for Scientific Information

Jennifer, B., A. Wendy ,B. Sophie, E .,Martin and S. Steve .2006. Seeding rate for weed control in organic spring wheat. Organic Agriculture Center of Canada, FinalResearchReportE-08.2006.

Johnson, J. W. and W.L. Hargrove.1988.Optimizing row spacing and seeding rate for soft red winter wheat. Agron.J.80:164-166.

Khan, M.A.,J. Anwar,A.Sattar and M.A.Akhtar.2001.Effect of seed rate on wheat yield under different sowing dates and row spacing. J. Agric. Res.39 (3-4):223-229. 
Khan, A.Z., H. Khan, R. Khan, Adel Ghoneim and A. Ebid 2002. Effect of sowing dates and seed rates on yield and yield components of wheat. Trendsin AppliedSci.Res., 2(6):529-534.

Kimber, G.and,E.R. Sears 1987. Evolution in the genus Triticum and the origin of cultivated wheat.Pp.154-164; In Heyne,E.G.(ed.), Wheat and wheat improvement, ed. Madison.

Kumpawt, B. S. 1998. Response of late sowed wheat to sowing method and seed rate. Indian J. Agron. 43(4): 650-652.

Malik, M. A., M. H. Rasheed and A. Razzaq. 1996. Row spacing study on two wheat varieties under rainfed conditions. Sarhad J. Agric. 12(1):31-36.

Marshall, G. C. and H. W. Ohm .1987. Yield responses of 16 winter wheat cultivars to row spacing and seeded rate. Agron. J. 79: 1027-1030.

Marwat, M. I., H. K. Ahmad, H. H. Khan and A. Khan .2002. Integrated weed management in wheat. Weed density, dry weed biomass, absolute growth rate and grain yield. Pakistan .J. Weed Sci. Res. 8(1-2):81-93.

Mehrvar M. R. and H. Asadi .2006. Agronomical and economical assessment of planting methods and seeding rates in irrigated wheat. J. Agron., 5(4):626-633.

Rafique,M.,A.Ahmad,N.Muhammad, M.Siddique and M. Kamran 1997. Effect of seeding densities and planting techniques on late sown wheat(Triticumaestivum L.) yield .J.Agric.Res.35(3):147-153.

Rajput, F.K.M., A.S. Arain, M.J., S.M. Alamand, A.W. Baloch 1989. The growth and yield of wheat as affected by different seed rates and row spacing. Sarhad J.Agric.5:479-482.

Samuel, A.M. 1990. Organically grown wheat-the effect of crop husbandry on grain quality. p.199-208. InAspects of Applied Biology 36,Cereal Quality III. Association of Applied Biologists, Warwick,UK.

Saritha, M. and Prasad Tollamadugu, N. V. K. V. 2019. The Status of Research and Application of Biofertilizers and Biopesticides: Global Scenario. In: Buddolla, V. (ed.) Recent Developments in Applied Microbiology and Biochemistry. Academic Press.

Satorre, E. H. 1999. Plant density and distribution as modifiers of growth \& yield. p.141-159.In E.H. Satorre \& G.A.Slafer(ed.) Wheat Ecology \& physiology of yield determination. Food Products Press, NewYork.

Schulthess, U., B. Feil and S.C. Jutzi.1997.Yield independent variation in grain nitrogen and phoshororus concentration among Ethiopian wheat.Agronomy Journal.89 (3):497-506.

Slafer, G.A. and E.H. Satorre 1999. An introduction to the physiological-ecologicala nalysis of wheat yield. In E.H. Satorre and G.A. Slafer (Eds.), Wheat: Ecology and physiology of yield determination.

Solie, J.B.,S.G.Solomon, K.P.Self,T.F.Peeper \& J.A.Koscelny.1991. Reduced row spacing for improved wheat yields in weed-free \& weed- infested fields. Transactions of the ASAE 34: 1654-1660.

Staggenborg ,S.A., Whitney,D.A., D.L. Fjell and J.P. Shroyer.2003. Seeding and nitrogen rates required to optimize winter wheat yields following grain sorghum and soybean.Agron.J.95:253-259.

Tanner, D.G., and W.M. Mwangi 1992. Current issues in wheat research and production in Eastern, Central and Southern Africa: Constraints and achievements. pp. 17-36. In: Tanner, D.G., and W.M. Mwangi (eds.). The Seventh Regional Wheat Workshop for Eastern, Central and Southern Africa. Nakuru, Kenya: CIMMYT. Tompkins, D.K.,G.E. Hultgjreen, A.T.Wright and D.B. Fowler.1991.Seed rate and row spacing of no- till winter wheat.Agron.J.83:684-688 